\title{
Molecular assessment of phylogenetic relationships in selected species/genera in the naviculoid diatoms (Bacillariophyta). I. The genus Placoneis
}

\author{
by \\ Katrin Bruder and Linda K. Medlin* \\ Alfred Wegener Institute for Polar and Marine Research, \\ Am Handelshafen 12, D-27570 Bremerhaven, Germany \\ With 19 figures and 4 tables
}

Bruder, K. \& L.K. Medlin (2007): Molecular assessment of phylogenetic relationships in selected species/genera in the naviculoid diatoms (Bacillariophyta). I. The genus Placoneis. - Nova Hedwigia 85: $331-352$.

\begin{abstract}
As part of a larger study to reconstruct evolutionary relationships within the naviculoid diatoms, phylogenetic analyses of several freshwater naviculoid species were performed using three different genes (SSU rRNA gene, LSU rRNA gene and rbcL gene), and the morphology of the sequenced species was investigated. This study focused on species of Placoneis, a genus that was separated from Navicula based on its chloroplast morphology, a feature that places it within the Cymbellales. The phylogenetic analyses also clearly place Placoneis in this order, but the relationships between the different genera varied with different genes. Navicula hambergii, whose allocation to Navicula sensu stricto was known to be wrong, is shown to belong to the genus Placoneis and is transferred to that genus. Its transfer is supported by both the phylogenetic analyses and the morphological investigation.
\end{abstract}

\section{Introduction}

The genus Navicula was described by Bory de Saint-Vincent in 1822 based on Navicula tripunctata (O.F.Müller) Bory. Within the diatoms, this genus was probably the largest and most diverse because "Navicula had traditionally been a dump for all bilaterally symmetrical raphid diatoms lacking particularly distinctive features" (Round et al. 1990, p. 566). Nevertheless, with electron microscopy and the investigation of living cells, the true morphological diversity of the genus became apparent, and many taxonomic revisions have been and are being conducted. As a result, many former Navicula spp. have been transferred to new genera, e.g., Haslea Simonsen

*Corresponding author, e-mail: Linda.Medlin@awi.de 
(1974), Proschkinia Karayeva (1978), Parlibellus E.J.Cox (1988), Luticola D.G.Mann (Round et al. 1990), Hippodonta Lange-Bertalot et al. (1996), Eolimna LangeBertalot \& W.Schiller in W.Schiller \& Lange-Bertalot (1997), Mayamaea LangeBertalot (1997), or old genera, e.g., Sellaphora Kützing, Placoneis Mereschkowsky, and Dickieia Berkeley have been resurrected (Mann 1989, Cox 1987, 2003, Mann 1994). Today, most diatomists agree that Navicula (sensu stricto) should be used only for species that belong to Navicula section Lineolatae sensu Cleve (1895) and Hustedt (1930). Navicula sensu stricto encompasses approximately 200 species, which predominantly (about 150 species) inhabit freshwater environments (Witkowski et al. 1998). However, the validity of the new or resurrected genera has not yet been assessed using molecular techniques.

It has long been evident that there is useful information about evolutionary history in gene sequences. The wide application of this method began with the appearance of the polymerase chain reaction (PCR) in mid-1980 (Saiki et al. 1988). Coupled with the direct dideoxynucleotide sequencing of amplified products, the technique became a powerful tool in life sciences. Sequences of several genes are now being used to assess phylogenetic relationships in the diatoms $[18 \mathrm{~S}, 16 \mathrm{~S}, t u f \mathrm{~A}, r b c \mathrm{~L}$ in Medlin et al. (1996, 2000); Cox 1 in Ehara et al. (2000); and rpoA (Fox \& Sorhannus 2003).

The SSU rRNA gene is the most widely used gene for inferring phylogenetic relationships (Van der Auwera \& De Wachter, 1998, Ludwig \& Klenk 2001). Thousands of partial and complete sequences (approx. $1800 \mathrm{bp}$ in eukaryotes) from prokaryotes, single-celled and multicellular eukaryotes can be found in internetavailable databases, such as GenBank (http://www.ncbi.nlm. nih.gov/). In diatoms, the gene has been used to study their position within the heterokont algae (e.g., Daugbjerg \& Andersen 1997), to reconstruct the evolution of the major classes (e.g., Medlin \& Kaczmarska 2004) or to assess the monophyly of diatom orders or genera (e.g., Beszteri et al. 2001) and the presence of cryptic species (Sarno et al. 2005).

The LSU rRNA gene comprises more highly variable areas than the SSU rRNA gene (Van der Auwera \& De Wachter 1998). This likely carries a stronger phylogenetic signal for discriminating closely related species as compared to the slower evolving SSU rRNA gene, but it may cause problems for reconstructing deep phylogenies because of saturation effects, i.e., the signal might be indistinct. Furthermore, highly variable sequences are difficult to align. Because of the large size of LSU rDNA (over $3300 \mathrm{bp}$ ) complete sequences of this gene are rare and typically sequences used for phylogenetic analyses are derived from parts of the gene, most notably approximately $600 \mathrm{bp}$ from the 5' end of 28S rDNA (D1/D2 region), one of the most highly variable regions in the gene.

Not all eukaryotic DNA is stored within the cell nucleus. Organelles, such as mitochondria or chloroplasts, contain their own DNA and such genomes usually consist of a single DNA molecule with each gene normally represented only once. The chloroplast genome contains predominantly protein-coding genes, which are used for phylogenetic analyses. The enzyme ribulose-1,5-bisphosphate carboxylase (RUBISCO) is responsible for carbon fixation. The $r b c \mathrm{~L}$ gene encoding the large subunit of RUBISCO is located in a single-copy region of the chloroplast genome. It 
is typically 1428-1434 bp in length and insertions or deletions are extremely rare (Soltis \& Soltis 1998).

The relative rates of evolution of the SSU rRNA and $r b c \mathrm{~L}$ genes vary among different groups. The $r b c \mathrm{~L}$ gene generally evolves about three times faster than SSU rDNA in angiosperms but is slower in the Orchidaceae (Soltis \& Soltis 1998). Within the phaeophytes, a slightly faster mutation rate of the $r b c \mathrm{~L}$ gene has been observed (Draisma \& Prud'homme van Reine, electronic source). Compared to SSU rDNA, the $r b c \mathrm{~L}$ gene appears more suited in diatoms to studies of evolution at order to generic levels of taxonomic hierarchy (Mann et al. 2001).

In order to estimate evolutionary relationships within the Naviculaceae (sensu Krammer \& Lange-Bertalot 1986) and to identify taxonomic problems, phylogenetic analyses of several freshwater naviculoid species were performed from cultures established from collecting sites in north Germany. Three different genes (SSU, LSU, and $r b c \mathrm{~L}$ ) were sequenced for each culture and phylogenies were reconstructed for each gene and a phylogenetic analysis based on a combined data set of all three genes was conducted. The morphology of the sequenced species was also investigated. We present here the first part of this study: an assessment of the genus Placoneis.

\section{Materials and methods}

\section{Cultures}

The cultures used in this study were established within the scope of the ALGATERRA project (http://www.algaterra.net/). Between November 2001 and September 2003, 220 samples were taken from 83 sites, representing several terrestrial, freshwater and brackish habitats in northern Germany (Fig. 1).

Cultures were initiated from these samples using a DY-IV medium (Andersen et al. 1997) mixed 2:1 with filter-sterilized (pore size: $0,1 \mu \mathrm{m}$ ) water from the sampling sites. After one to four days, clonal cultures were isolated from these initial cultures. For isolates from alkaline, acid or brackish habitats, the media was adjusted by addition of sodium hydroxide, hydrochloric acid or IMR-media (Eppley et al. 1967). Most of these isolates still contained small flagellates and in order to remove these flagellates from the cultures a small number of diatom cells was transferred to fresh medium several times and then grown on agar plates (prepared from liquid media) for one to three weeks. A small number of diatom cells were transferred from these plates to liquid medium. If necessary the entire procedure was repeated several times. All isolates were grown under a 14/10 light/dark cycle with photon flux densities between 30 and $120 \mu \mathrm{M}$ photons $\mathrm{m}^{-2} \mathrm{~s}^{-1}$ at $15^{\circ} \mathrm{C}$. A list of all cultured species is presented in Table 1.

\section{DNA Methods}

DNA ISOLATION: Culture material was concentrated by filtration and quick-frozen in liquid nitrogen. Nucleic acids were extracted using the Invisorb Spin Plant Mini Kit (Invitek GmbH, Berlin, Germany). The given protocol was only modified by a duplication of the two washing steps.

PCR: For each culture, the small subunit rRNA coding gene (SSU rDNA), the D1-D2 region of the large-subunit rRNA gene (LSU rDNA) and the middle part of the ribulose-1,5-bisphosphate carboxylase/oxygenase large subunit gene $(r b c \mathrm{~L})$ were amplified using the polymerase chain reaction (PCR; Saiki et al. 1988, Medlin et al. 1988). In the $r b c \mathrm{~L}$ gene sequence of Rhizosolenia setigera (GenBank accession number: AF015568) the sequence of the primers F3 and R3 can be found at the position 292-314 and 1028-1051, respectively. The primers and conditions used for PCR are shown in the Tables 2 and 3. The PCR-products were purified by MinElute ${ }^{\mathrm{TM}}$ PCR Purification Kit (QIAGEN, Germany) according to the manufacturer's protocol. PCR products with multiple bands were purified by excising from a $1 \%$ agarose gel. 


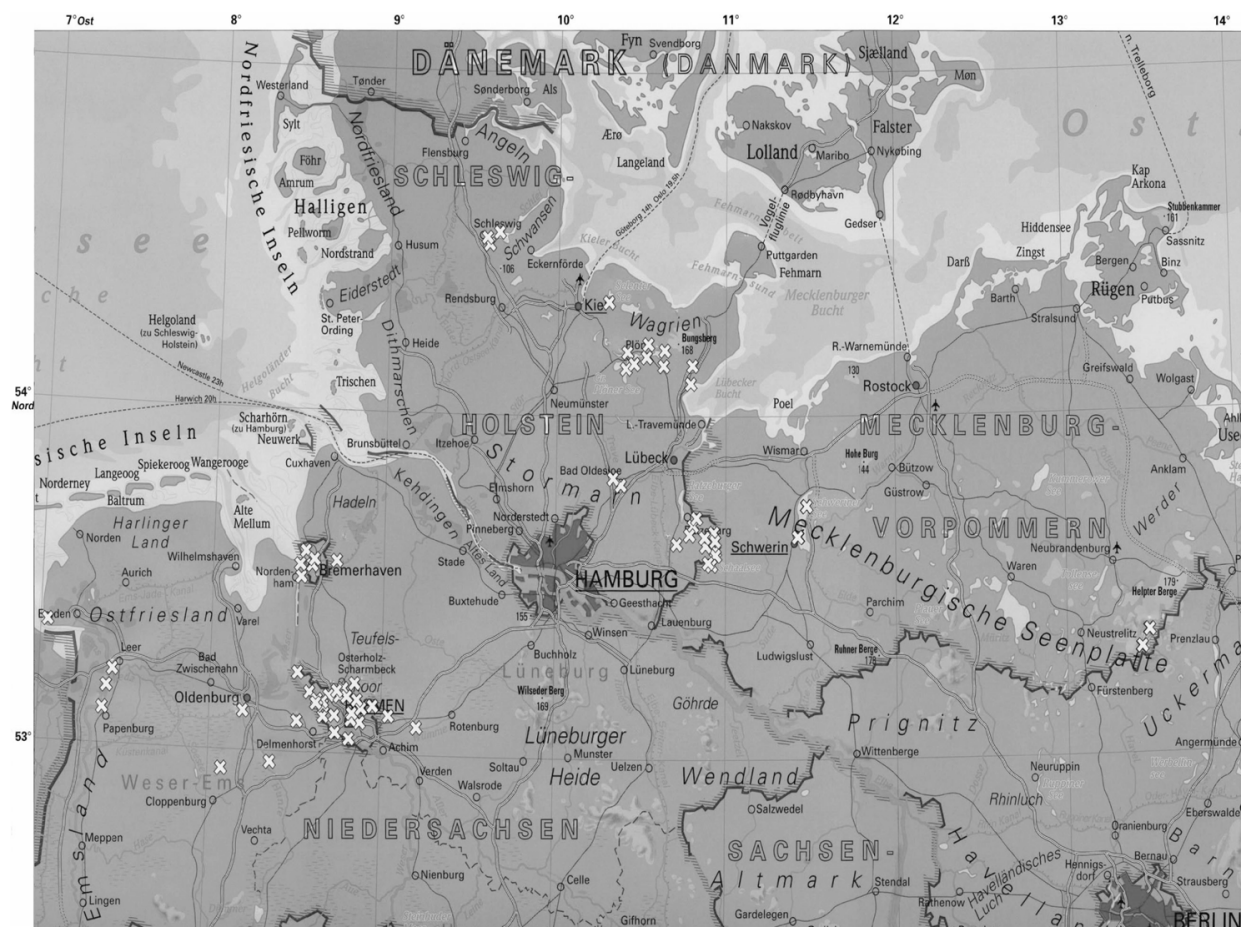

Fig. 1. Sampling sites (map from Stiefel Verlag GmbH, Lenting).

SEQUENCING: PCR products were sequenced directly on both strands using Big Dye Terminator v3.1 sequencing chemistry (Applied Biosystems, CA, USA). For the LSU rRNA gene and the $r b c$ L-gene the sequencing reactions were made using the same primers already used in the PCR. Because of the length of the SSU rRNA gene, additional internal primers (Elwood et al. 1985) were used. Sequencing products were purified by DyeEx ${ }^{\mathrm{TM}}$ Spin Kit (QIAGEN, Germany) and electrophoresed on an ABI 3100 Avant sequencer (Applied Biosystems, CA, USA).

\section{Sequence Analysis}

Sequences exported from corrected electropherograms were assembled using SeqMan (Lasergene package, DnaStar, Madison, WI, USA). Accession numbers for the three genes are presented in Table 1. For the protein-coding $r b c \mathrm{~L}$-gene, the protein-sequence was also checked. Three species had internal stop codons in the primary sequence and these species are marked as pseudogenes in their GenBank entry. The alignment of the SSU rDNA sequences was done with ARB using the secondary structure. The sequences of the D1-D2 region and the $r b c \mathrm{~L}$ Gene were aligned using ClustalX (Thompson et al. 1997) and checked manually using ProSeq v 2.9 beta (Filatov 2002). The rRNA genes show hypervariable regions for which it is difficult to obtain an unambiguous alignment. These highly variable sites (e.g., V4) were excluded from the alignment. The final data set contained 3226 bp of which 896 were informative for parsimony analyses.

To obtain three combinable alignments with the same set of species an alignment was computed for each gene using only the sequences of the cultures established for this study (Table 1). A second alignment was made for each gene using additional sequences obtained from GenBank (Table 4). For the individual genes, the analysis was performed on the combined datasets of GenBank and ALGATERRA sequences. For the analysis of the combined genes, only the sequences generated in 


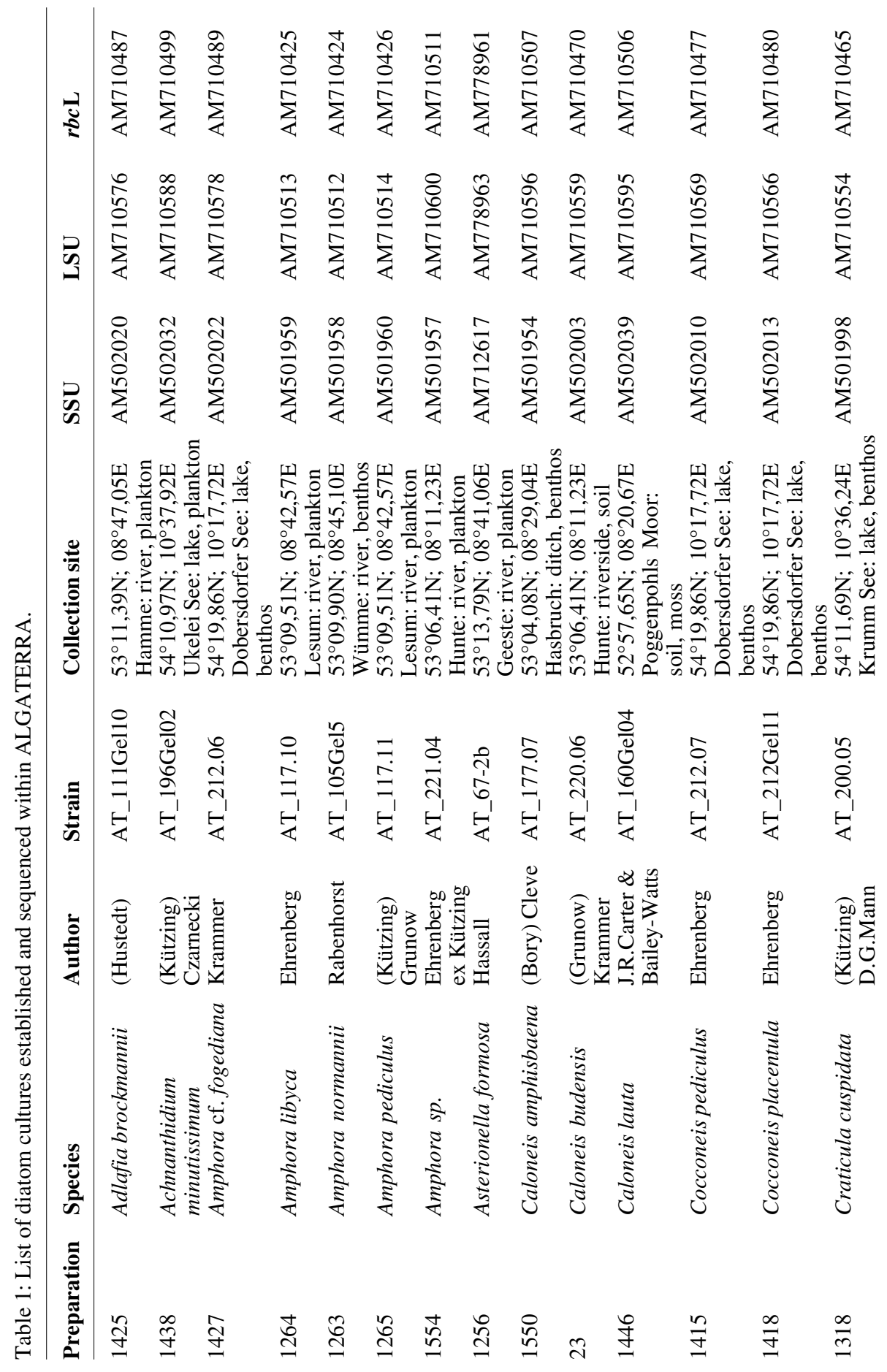




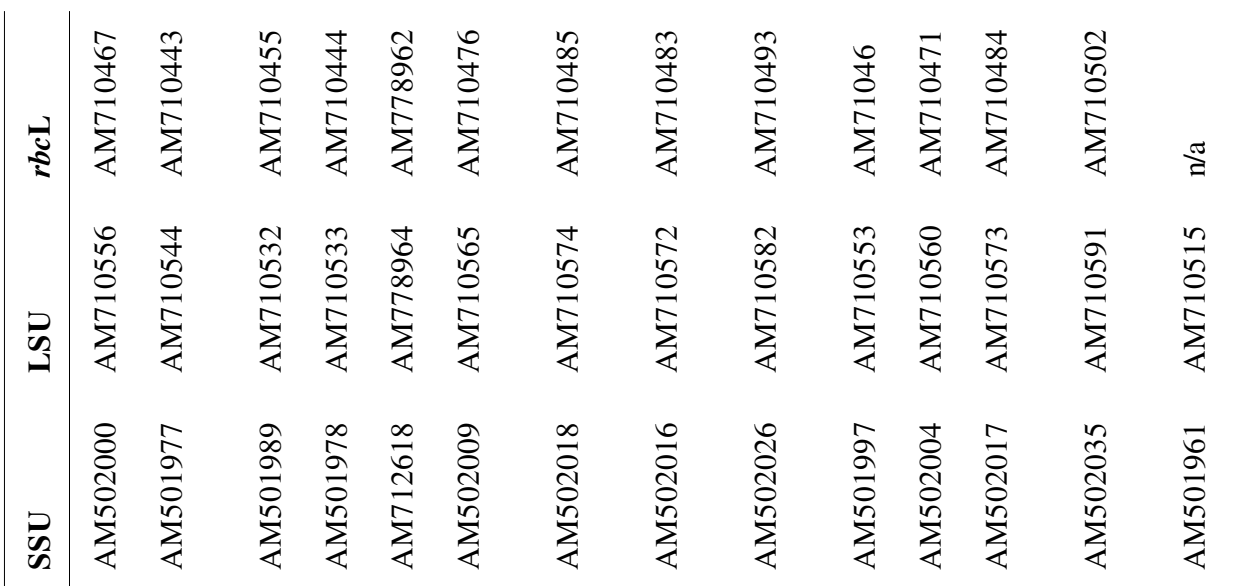

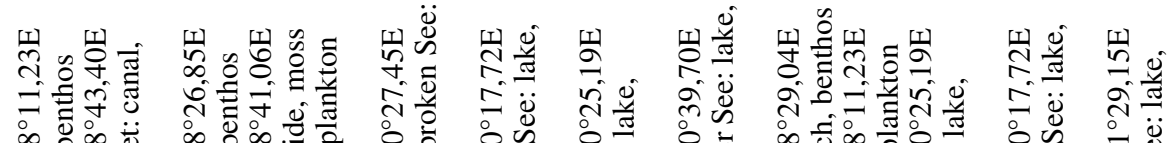

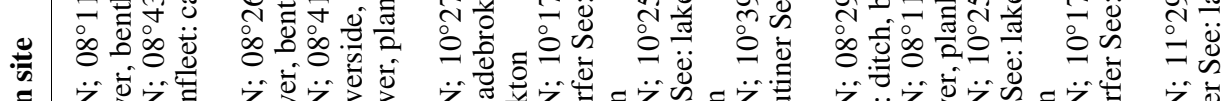

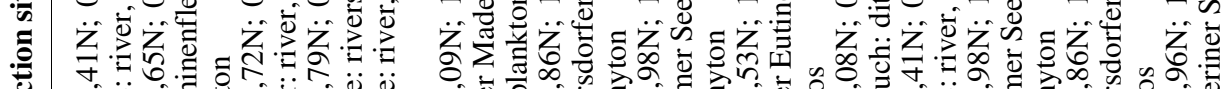

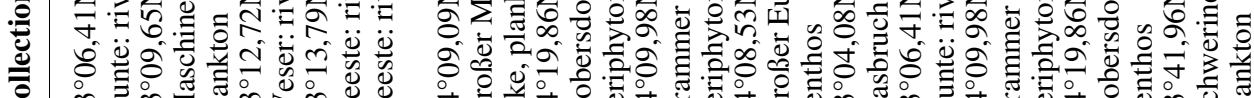

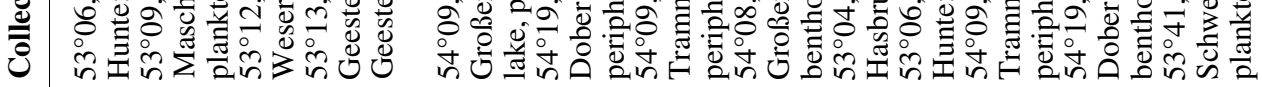

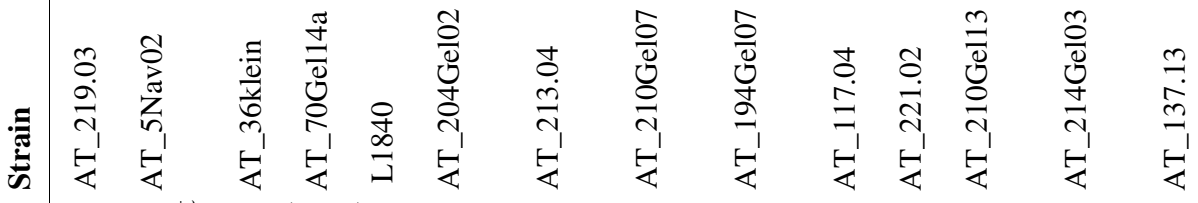

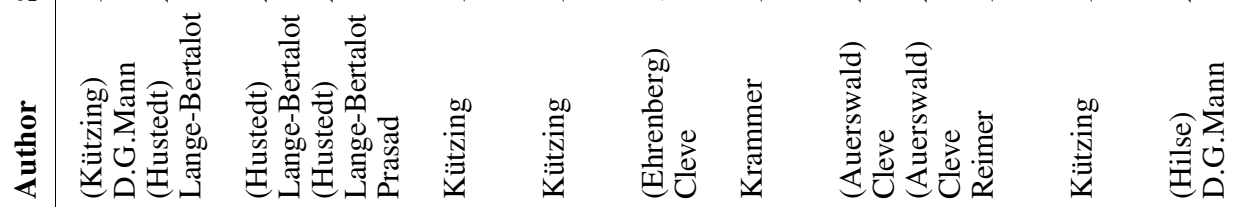

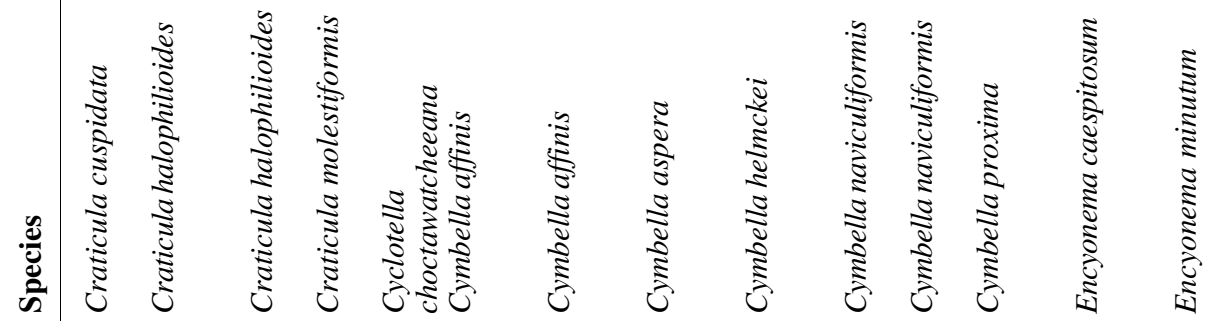
$\Xi$

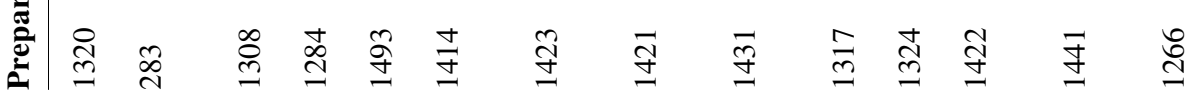




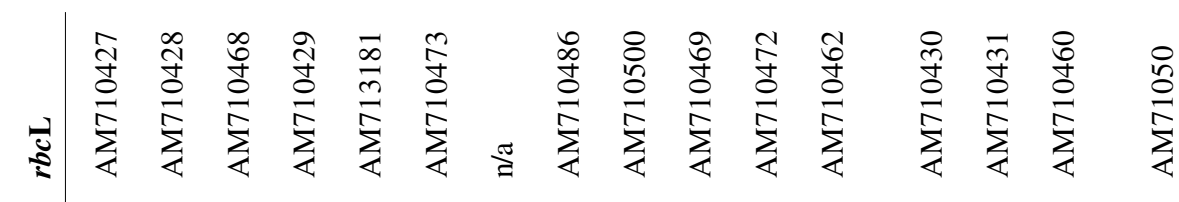

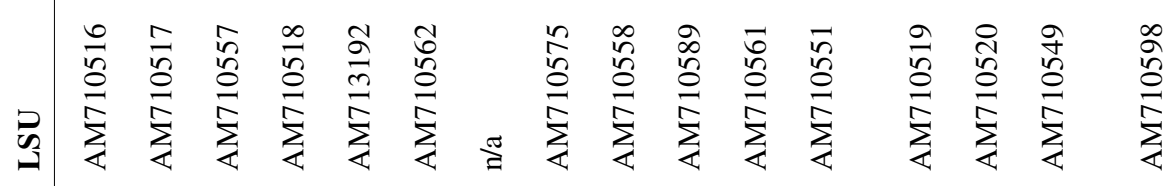

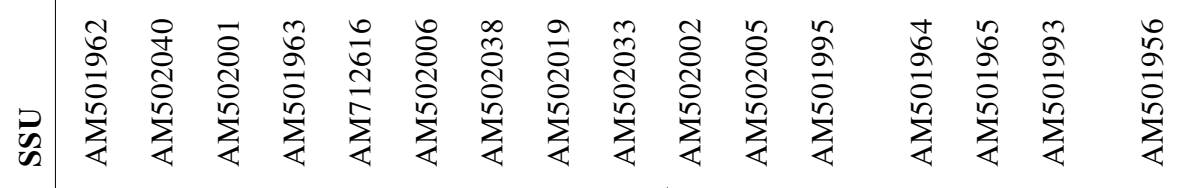

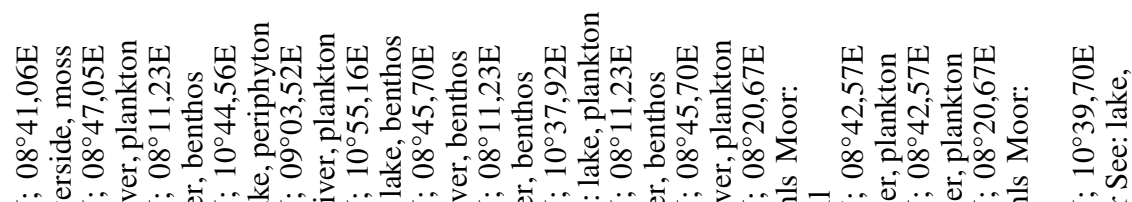

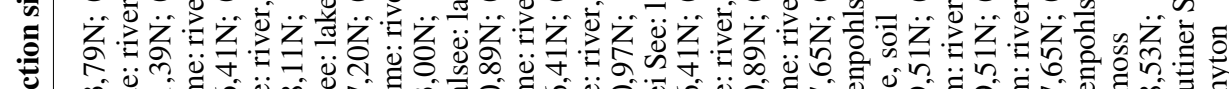
ஸें ñ

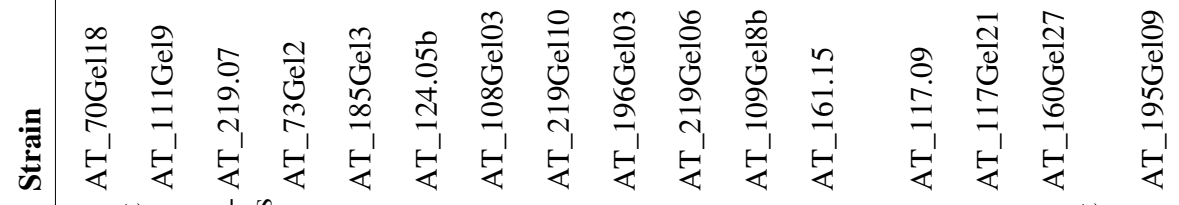

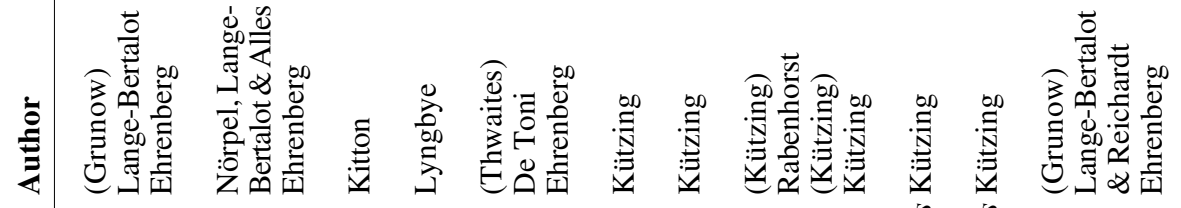

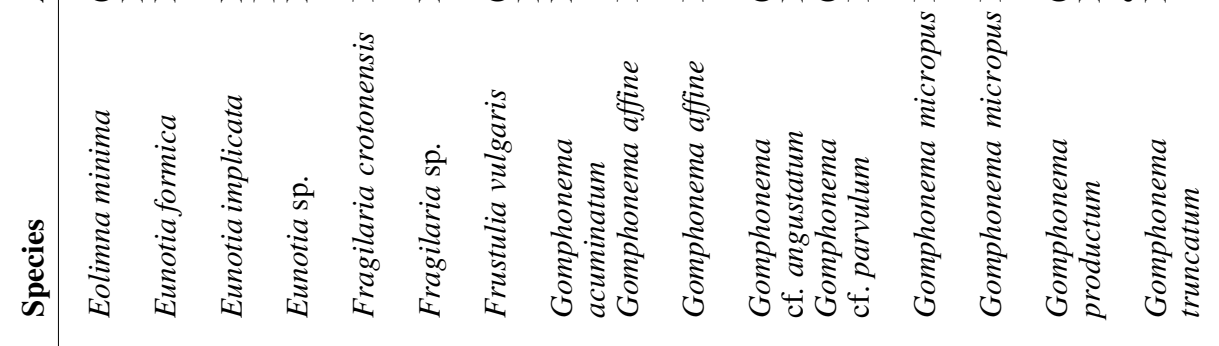

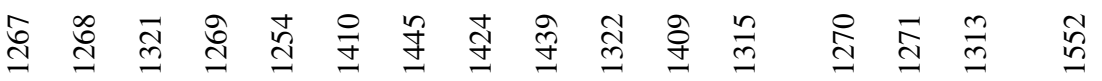




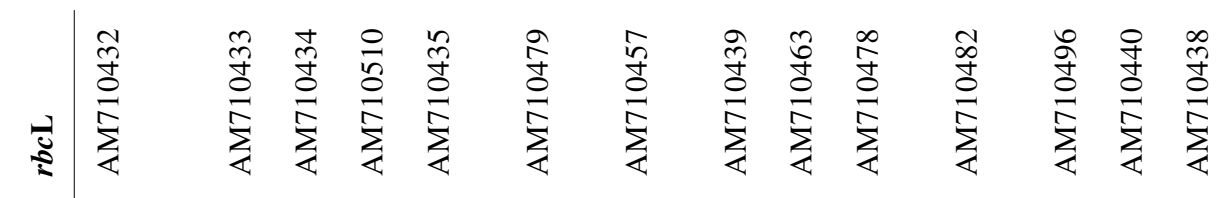

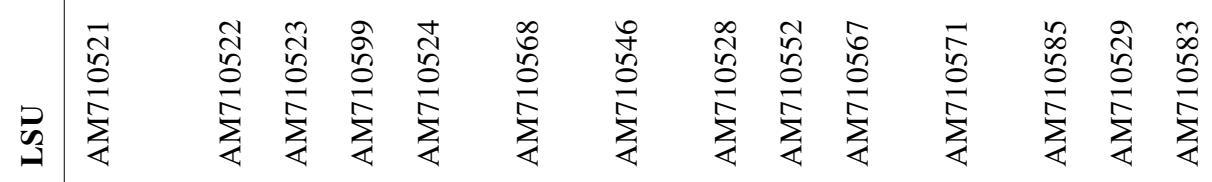

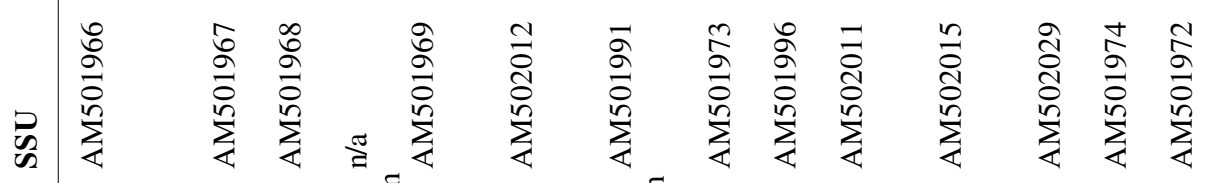

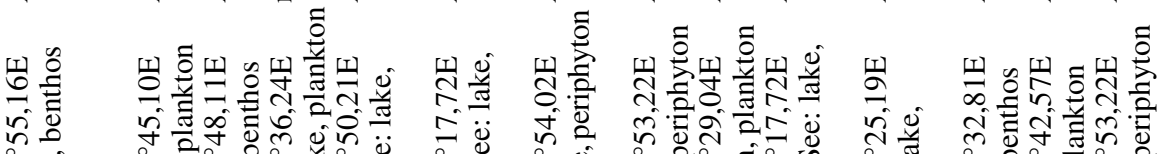

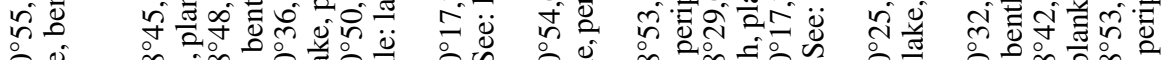

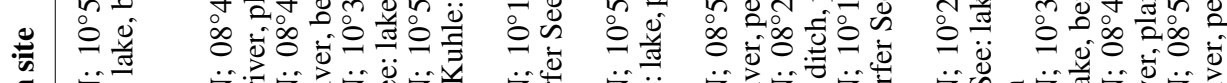

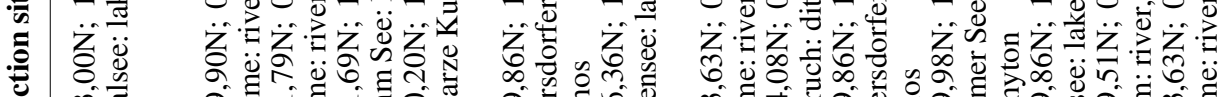

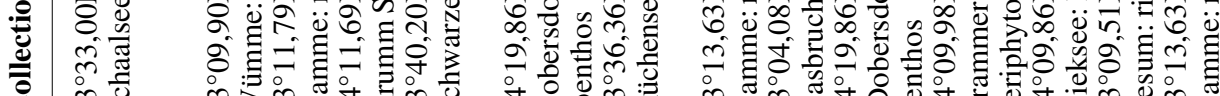

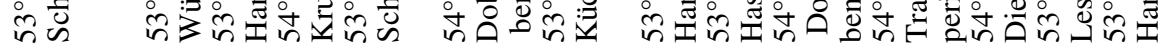

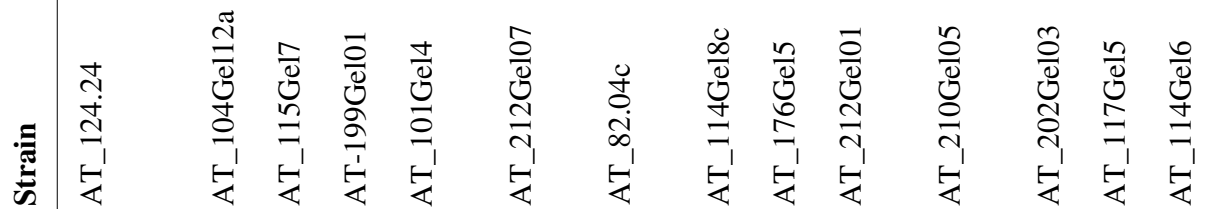

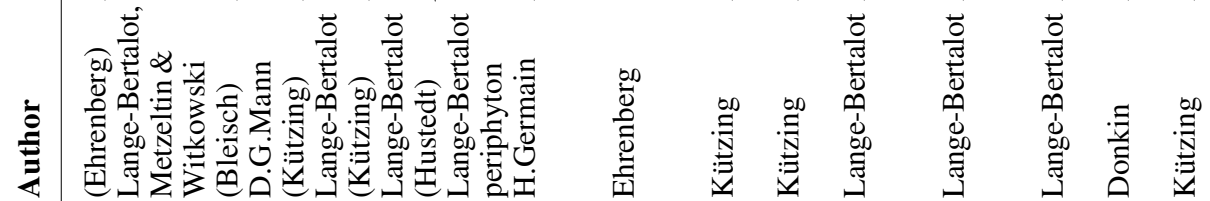

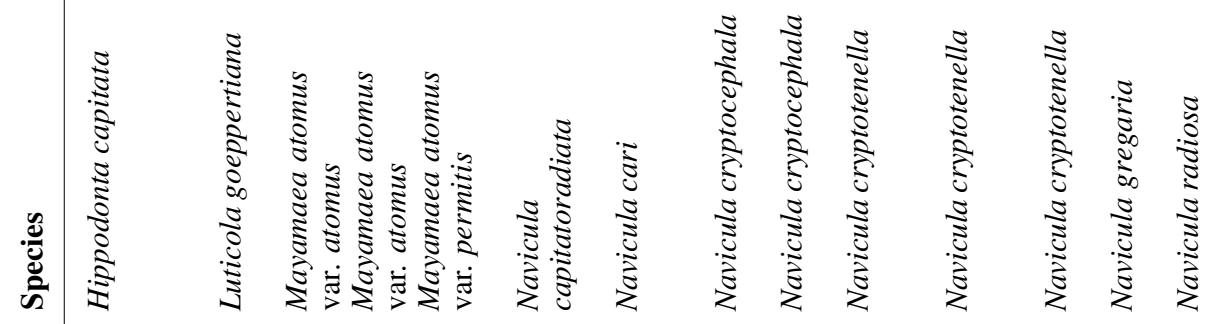

$\overline{\underline{\pi}}$

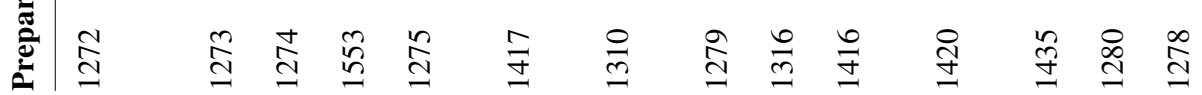




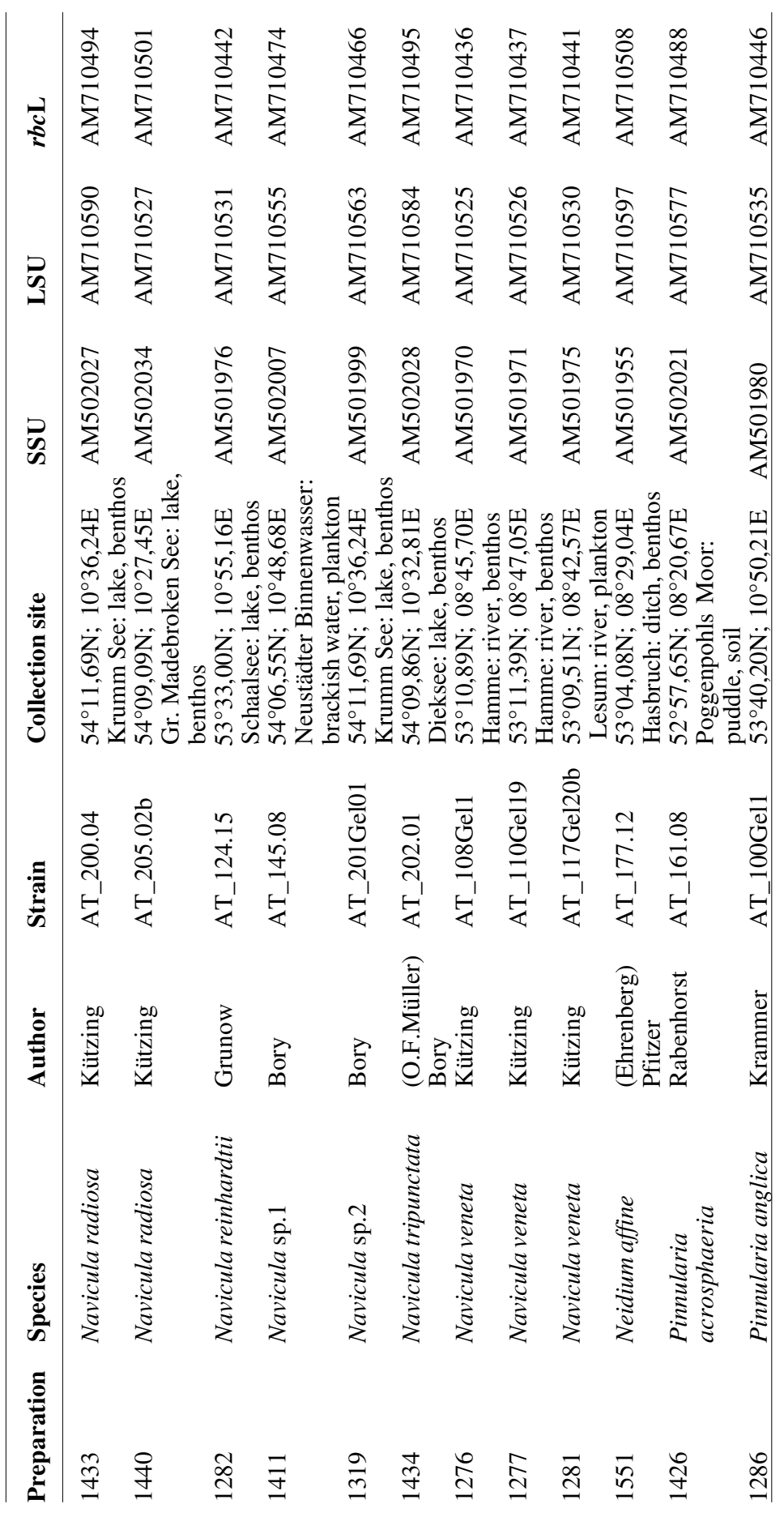


Table 2: Primers used for PCR

\begin{tabular}{|c|c|c|c|}
\hline Gene & Primer & Sequence (5' ® 3') & Author \\
\hline \multirow{2}{*}{$\begin{array}{l}\text { SSU } \\
\text { rRNA }\end{array}$} & $1 \mathrm{~F}$ & AAC CTG GTT GAT CCT GCC AGT & Medlin et al. (1988), without \\
\hline & $1528 \mathrm{R}$ & TGA TCC TTC TGC AGG TTC ACC TAC & $\begin{array}{l}\text { Medlin et al. (1988), without } \\
\text { polylinker }\end{array}$ \\
\hline LSU & DIRF & ACC CGC TGA ATT TAA GCA TA & Scholin et al. (1994) \\
\hline rRNA & $\mathrm{D} 2 \mathrm{CR}$ & CCT TGG TCC GTG TTT CAA GA & Scholin et al. (1994) \\
\hline \multirow{2}{*}{$r b c \mathrm{~L}$} & F3 & GCT TAC CGT GTA GAT CCA GTT CC & Beszteri, unpubl. \\
\hline & R3 & ССТ TCT АAT TTA CCA ACA ACT G & Beszteri, unpubl. \\
\hline
\end{tabular}

Table 3: PCR programs

\begin{tabular}{|c|c|c|c|c|}
\hline \multirow[t]{2}{*}{ Cycle step } & \multicolumn{2}{|c|}{ SSU and LSU rRNA } & \multicolumn{2}{|c|}{$r b c \mathrm{~L}$} \\
\hline & Temperature & Time & Temperature & Time \\
\hline Initial denaturation & $94^{\circ} \mathrm{C}$ & $7 \mathrm{~min}$ & $94^{\circ} \mathrm{C}$ & $10 \mathrm{~min}$ \\
\hline Denaturation & \multicolumn{2}{|c|}{ Cycle } & \multicolumn{2}{|l|}{ Cycle } \\
\hline Annealing & $54^{\circ} \mathrm{C}$ & $4 \mathrm{~min}$ & $56^{\circ} \mathrm{C}$ & $1 \mathrm{~min}$ \\
\hline Elongation & $72^{\circ} \mathrm{C}$ & $2 \mathrm{~min}$ & $72^{\circ} \mathrm{C}$ & $2 \min$ \\
\hline Cycle repetitions & \multicolumn{2}{|l|}{35} & \multirow[t]{2}{*}{31} & \\
\hline Final elongation & $72^{\circ} \mathrm{C}$ & $7 \mathrm{~min}$ & & $10 \mathrm{~min}$ \\
\hline
\end{tabular}

the ALGATERRA project were used so that only species with sequence data for all three genes were used.

Phylogenetic analyses were performed using PAUP* 4.0b10 (Swofford 1998). In all analyses, the data set was rooted using one centric (Cyclotella choctawatcheeana) and two araphid diatoms (Fragilaria crotonensis and Asterionella formosa), as the use of several outgroup taxa improves the analyses (Swofford et al. 1996). For maximum likelihood (ML) and distance based tree calculations, likelihood scores of different nucleotide substitution models were compared on a neighbor joining tree using Modeltest 3.0 (Posada \& Crandall 1998). Based on the Akaike Information Criterion (AIC) the best fit model $(\mathrm{GTR}+\mathrm{I}+\mathrm{G})$ was identified for all genes. This was used for phylogenetic analyses using ML and neighbor joining (NJ) tree inference with ML distances. Maximum parsimony (MP) and ML trees were obtained in heuristic searches, with 10 random taxon additions. To assess confidence in clades recovered, bootstrapping of MP and NJ analyses was made with 1000 replicates (Felsenstein 2004). If necessary, a time limit of 15 minutes was set for each replicate. For the combined dataset, 100 replicates of the partition homogeneity test, as implemented in PAUP, were performed.

\section{Microscopy}

For identification and morphological investigations of the cultures, light and scanning microscopy were used. Living cells as well as cleaned frustules were examined and photographed by bright field microscopy using a ZEISS Axioplan microscope with a AxioCam MRc digital camera. To remove all organic material, the cells were oxidized with $\mathrm{KMnO}_{4}$ for $12-16$ hours. Then $\mathrm{HCl}$ was added and the mixture boiled until it turned light yellow. The liquid was discarded and the frustules were 
Table 4: List of species of diatoms obtained from GenBank and their accession numbers of the used gene sequences

\begin{tabular}{|c|c|c|c|c|c|}
\hline Species & & Authority & SSU rRNA & LSU rRNA & $r b c \mathrm{~L}$ \\
\hline Achnanthes & bongranii & $\begin{array}{l}\text { (M.Peragallo) } \\
\text { A.Mann }\end{array}$ & AJ535150 & & \\
\hline Achnanthes & brevipes & C.Agardh & AY485476 & & \\
\hline Achnanthes & minutissima & Kützing & AJ866992 & & \\
\hline Achnanthes & sp. 1 & Bory & AY485496 & & \\
\hline Achnanthes & sp. 2 & Bory & AJ535151 & & \\
\hline Achnanthidium & $\imath$ cf. longipes & C.Agardh & AY485500 & & \\
\hline Amphora & cf. capitellata & Frenguelli & AJ535158 & & \\
\hline Amphora & cf. proteus & W.Gregory & AJ535147 & & \\
\hline Amphora & coffeaeformis & (C.Agardh) Kütz. & AY485498 & AF417682 & \\
\hline Amphora & montana & Krasske & AJ243061 & & \\
\hline Amphora & & Ehrenberg ex Kützing & AB 183590 & & \\
\hline Anomoeoneis & sphaerophora & (Kützing) Pfitzer & AJ535153 & & \\
\hline Bacillaria & paxillifer & (Müller) Hendey & M87325 & AF417678 & \\
\hline Campylodiscus & ralfsii & C.Agardh & AJ535162 & & \\
\hline Cocconeis & cf. molesta & Kützing & AJ535148 & & \\
\hline Cyclotella choc & ctawatcheeana & A.K.S. Prasad & & AJ878463 & \\
\hline Cylindrotheca & closterium & $\begin{array}{l}\text { (Ehrenberg) } \\
\text { Reimer \& Lewin }\end{array}$ & M87326 & & \\
\hline Cymatopleura & elliptica & (Brébisson) W.Smith & AJ867030 & & \\
\hline Cymbella & cymbiformis & W.Smith & AJ535156 & & \\
\hline Diadesmis & gallica & W.Smith & AJ867023 & & \\
\hline Dickieia & ulvacea & Berkeley & AY485462 & & \\
\hline Encyonema & cf. sinicum & Krammer & & & AY571754 \\
\hline Encyonema & triangulatum & (Ehrenberg) Kützing & AJ535157 & & \\
\hline Entomoneis & alata & (Ehrenberg) Ehrenberg & AY 485497 & & \\
\hline Entomoneis & paludosa & (W.Smith) Reimer & AY485468 & & \\
\hline Entomoneis & cf. alata & (Ehrenberg) Ehrenberg & AJ535160 & & \\
\hline Entomoneis & & Ehrenberg & & AF417683 & \\
\hline Eolimna & minima & $\begin{array}{l}\text { (Grunow) Lange- } \\
\text { Bertalot }\end{array}$ & AJ 243063 & & \\
\hline Eolimna & subminuscula & (Mangin) Moser & AJ243064 & & \\
\hline Eunotia & minor & (Kützing) Grunow & & & AY571744 \\
\hline Eunotia & bilunaris & (Ehrenberg) Mills & AJ866995 & & \\
\hline Eunotia & $\begin{array}{l}\text { cf. pectinalis } \\
\text { f. minor }\end{array}$ & (Kützing) Rabenhorst & AJ535146 & & \\
\hline Eunotia & $\begin{array}{l}\text { formica var. } \\
\text { sumatrana }\end{array}$ & Hustedt & AB085830 & & \\
\hline Eunotia & $\begin{array}{l}\text { monodon var. } \\
\text { asiatica }\end{array}$ & Skvortsov & AB085831 & & \\
\hline Eunotia & pectinalis & (Kützing) Rabenhorst & AB085832 & & \\
\hline Eunotia & sp. & Ehrenberg & AJ535145 & & \\
\hline Fragilaria & crotonensis & Kitton & AF525662 & & \\
\hline Asterionella & formosa & Hassall & AF525657 & & \\
\hline Fragilariopsis & cylindrus & Hasle & AY672802 & AF417657 & \\
\hline Gomphonema & capitatum & Ehrenberg & & & AY571751 \\
\hline Gomphonema & parvulum & (Kützing) Kützing & AJ243062 & & \\
\hline Gomphonema & pseudaugur & Lange-Bertalot & AB 085833 & & \\
\hline Gyrosigma & limosum & $\begin{array}{l}\text { Sterrenburg \& } \\
\text { Underwood }\end{array}$ & AY485516 & & \\
\hline $\begin{array}{l}\text { Haslea } \\
\text { Haslea }\end{array}$ & $\begin{array}{l}\text { crucigera } \\
\text { nipkowii }\end{array}$ & $\begin{array}{l}\text { (W.Smith) Simonsen } \\
\text { (Meister) Poulin \& } \\
\text { G.Massé }\end{array}$ & $\begin{array}{l}\text { AY485482 } \\
\text { AY485488 }\end{array}$ & & \\
\hline
\end{tabular}




\begin{tabular}{|c|c|c|c|c|c|}
\hline \multicolumn{2}{|l|}{ Species } & \multirow{2}{*}{$\begin{array}{l}\text { Authority } \\
\text { (Gaillon) Simonsen }\end{array}$} & \multirow{2}{*}{$\begin{array}{l}\text { SSU rRNA } \\
\text { AY485523 }\end{array}$} & \multirow[t]{2}{*}{ LSU rRNA } & \multirow[t]{2}{*}{$r b c \mathrm{~L}$} \\
\hline Haslea & ostrearia & & & & \\
\hline Haslea & pseudostrearia & $\begin{array}{l}\text { G.Massé, Rincé } \\
\text { \& E.J.Cox }\end{array}$ & AY485524 & & \\
\hline Lyrella & atlantica & $\begin{array}{l}\text { (A.Schmidt) } \\
\text { D.G.Mann }\end{array}$ & AJ544659 & & AY571747 \\
\hline Lyrella & hennedyi & $\begin{array}{l}\text { (W.Smith) Stickle } \\
\text { \& D.G.Mann }\end{array}$ & & & AY571755 \\
\hline Lyrella & sp. & N.I. Karajeva & & & AY571756 \\
\hline Lyrella & sp. 2 & N.I. Karajeva & AJ535149 & & \\
\hline Navicula & $\begin{array}{l}\text { atomus var. } \\
\text { permitis }\end{array}$ & $\begin{array}{l}\text { (Hustedt) } \\
\text { Lange-Bertalot }\end{array}$ & AJ867024 & & \\
\hline Navicula & $\begin{array}{l}\text { cf. duerren- } \\
\text { bergiana }\end{array}$ & Hustedt & & & AY571749 \\
\hline Navicula & cf. erifuga & Lange-Bertalot & & AF417679 & \\
\hline Navicula & $\begin{array}{l}\text { cryptocephala } \\
\text { var. veneta }\end{array}$ & $\begin{array}{l}\text { (Kützing) } \\
\text { Rabenhorst }\end{array}$ & AJ297724 & & \\
\hline Navicula & diserta & Hustedt & AJ535159 & & \\
\hline Navicula & lanceolata & (C.Agardh) Kützing & AY485484 & & \\
\hline Navicula & pelliculosa & $\begin{array}{l}\text { (Brébisson ex } \\
\text { Kützing) Hilse }\end{array}$ & AY485454 & & \\
\hline Navicula & phyllepta & Kützing & AY485456 & & \\
\hline Navicula & ramosissima & (C.Agardh) Cleve & AY485512 & & \\
\hline Navicula & salinicola & Hustedt & & & AY604699 \\
\hline Navicula & saprophila & Lange-Bertalot \& Bonik & AJ867025 & & \\
\hline Navicula & sclesviscensis & & AY485483 & & \\
\hline Navicula & sp. & Bory & AY485513 & & \\
\hline Navicula & sp. 2 & Bory & AY485502 & & \\
\hline Navicula & sp. 3 & Bory & AY485460 & & \\
\hline Nitzschia & amphibia & Grunow & AJ867277 & & \\
\hline Nitzschia & communis & Rabenhorst & AJ867278 & AF417661 & \\
\hline Nitzschia & cf. frustulum & (Kützing) Grunow & AJ535164 & AF417671 & \\
\hline Nitzschia & sigma & (Kützing) W.Smith & AJ867279 & & \\
\hline Nitzschia & vitrea & G.Norman & AJ867280 & & \\
\hline Pauliella & taeniata & $\begin{array}{l}\text { (Grunow) Round } \\
\& \text { Basson }\end{array}$ & AY485528 & AF417680 & \\
\hline Peridinium bal & lticum endosymb & biont & Y10566 & & \\
\hline Peridinium fol & iaceum endosym & abiont & Y10567 & & \\
\hline Petroneis & humerosa & $\begin{array}{l}\text { (Brébisson ex W.Smith } \\
\text { Stickle \& D.G.Mann }\end{array}$ & & & AY571757 \\
\hline Phaeodactylum & tricornutum & Bohlin & AY485459 & AF417681 & \\
\hline Pinnularia & cf. interrupta & W.Smith & AJ544658 & & \\
\hline Pinnularia & rupestris & Hantzsch & AJ867027 & & \\
\hline Pinnularia & sp. & Ehrenberg & AJ535154 & & \\
\hline Placoneis & $\begin{array}{l}\text { cf. parael- } \\
\text { ginensis }\end{array}$ & Lange-Bertalot & & & AY571753 \\
\hline Placoneis & constans & (Hustedt) E.J.Cox & & & AY571752 \\
\hline Pleurosigma & intermedium & W.Smith & AY485489 & & \\
\hline Pleurosigma & planktonicum & H.- J.Schrader & AY485514 & & \\
\hline Pleurosigma & sp. & W.Smith & AY485515 & & \\
\hline Pleurosigma & sp. 2 & W.Smith & AF525664 & & \\
\hline $\begin{array}{l}\text { Pseudo- } \\
\text { gomphonema }\end{array}$ & $\begin{array}{l}\text { cf. kamtscha- } \\
\text { ticum }\end{array}$ & (Grunow) Medlin & & & AY571748 \\
\hline $\begin{array}{l}\text { Pseudo- } \\
\text { gomphonema }\end{array}$ & sp. 1 & Medlin & AJ535152 & & \\
\hline
\end{tabular}




\begin{tabular}{|c|c|c|c|c|c|}
\hline Species & & Authority & SSU rRNA & LSU rRNA & $r b c \mathrm{~L}$ \\
\hline $\begin{array}{l}\text { Pseudo- } \\
\text { gomphonema }\end{array}$ & sp. 2 & Medlin & AF525663 & & \\
\hline Rossia & sp. & M.Voigt & AJ535144 & & \\
\hline Sellaphora & bacillum & (Ehrenberg) Mann & & & AY571745 \\
\hline Sellaphora & laevissima & (Kützing) Mann & AJ544655 & & \\
\hline Sellaphora & pupula & $\begin{array}{l}\text { (Kützing) } \\
\text { Mereschkowsky }\end{array}$ & AJ544649 & & AY571746 \\
\hline Sellaphora & $\begin{array}{l}\text { pupula var. } \\
\text { captitata }\end{array}$ & $\begin{array}{l}\text { (Skvortsov \& } \\
\text { K.I.Meyer) Poulin }\end{array}$ & AJ535155 & & \\
\hline Seminavis & cf. robusta & Danielidis \& D.G.Mann & & & AY571750 \\
\hline Stauroneis & constricta & (W.Smith) Cleve & AY485521 & & \\
\hline Surirella & angusta & Kützing & AJ867028 & & \\
\hline Surirella & brebissoni & $\begin{array}{l}\text { Krammer \& } \\
\text { Lange-Bertalot }\end{array}$ & AJ867029 & & \\
\hline Surirella & $\begin{array}{l}\text { fastuosa var. } \\
\text { cuneata }\end{array}$ & $\begin{array}{l}\text { (A.Schmidt) H.Pera- } \\
\text { gallo \& M.Peragallo }\end{array}$ & AJ535161 & & \\
\hline Tryblionella & apiculata & $\begin{array}{l}\text { (W.Gregory) } \\
\text { D.G.Mann }\end{array}$ & M87334 & & \\
\hline \multicolumn{3}{|c|}{ uncultured Eunotia-like diatom } & AY821975 & & \\
\hline Undatella & sp. & Paddock \& P.A.Sims & AJ535163 & & \\
\hline
\end{tabular}

washed 4 times with distilled water. The cleaned frustules were stored in distilled water. Permanent slides were made in Naphrax. For electron microscopy, coverslips were attached to aluminium specimen stubs with double-sided adhesive tape. Cleaned frustules were pipetted onto stubs, which were platinum-coated with a sputter coater (Emscope SC 500). Electron micrographs of cleaned frustules were taken at 10kV accelerating voltage on a Quanta FEG 200F, a PHILIPS XL30 ESEM or an I.S.I. DS-130.

\section{Results}

The phylogenetic trees generated in this study clearly show that Placoneis, consisting in our analysis of Placoneis elginensis, and an unidentified species, is distinct from Navicula sensu stricto and that $N$. hambergii belongs to Placoneis because it diverged at the base of or within the genus in most trees (Figs 2-5). The monophyly of $N$. hambergii and Placoneis was well supported, but its relationship/monophyly to other genera in the order Cymbellales varied with the gene used. In the SSU tree with the ML analysis, Placoneis is monophyletic and sister to clade containing Cymbella, Gomphonema, and Encyonema, but this relationship is unsupported (Fig. 2). In the LSU tree using ML analyses, Placoneis is sister to a clade with Cymbella and Gomphonema, and Encyonema is sister to both of these (Fig. 3). In the RbcL tree, Cymbella is not monophyletic and one species falls at the base of the Placoneis clade (Fig. 4). Gomphonema and Encyonema are separate lineages basal to the Placoneis/Cymbella clade. In the combined analysis of all three genes, Placoneis is a well-supported monophyletic clade sister to Cymbella. Again Encyonema and Gomphonema are basal to this lineage. All four analyses place Placoneis in the Cymbellales (Fig. 5). 


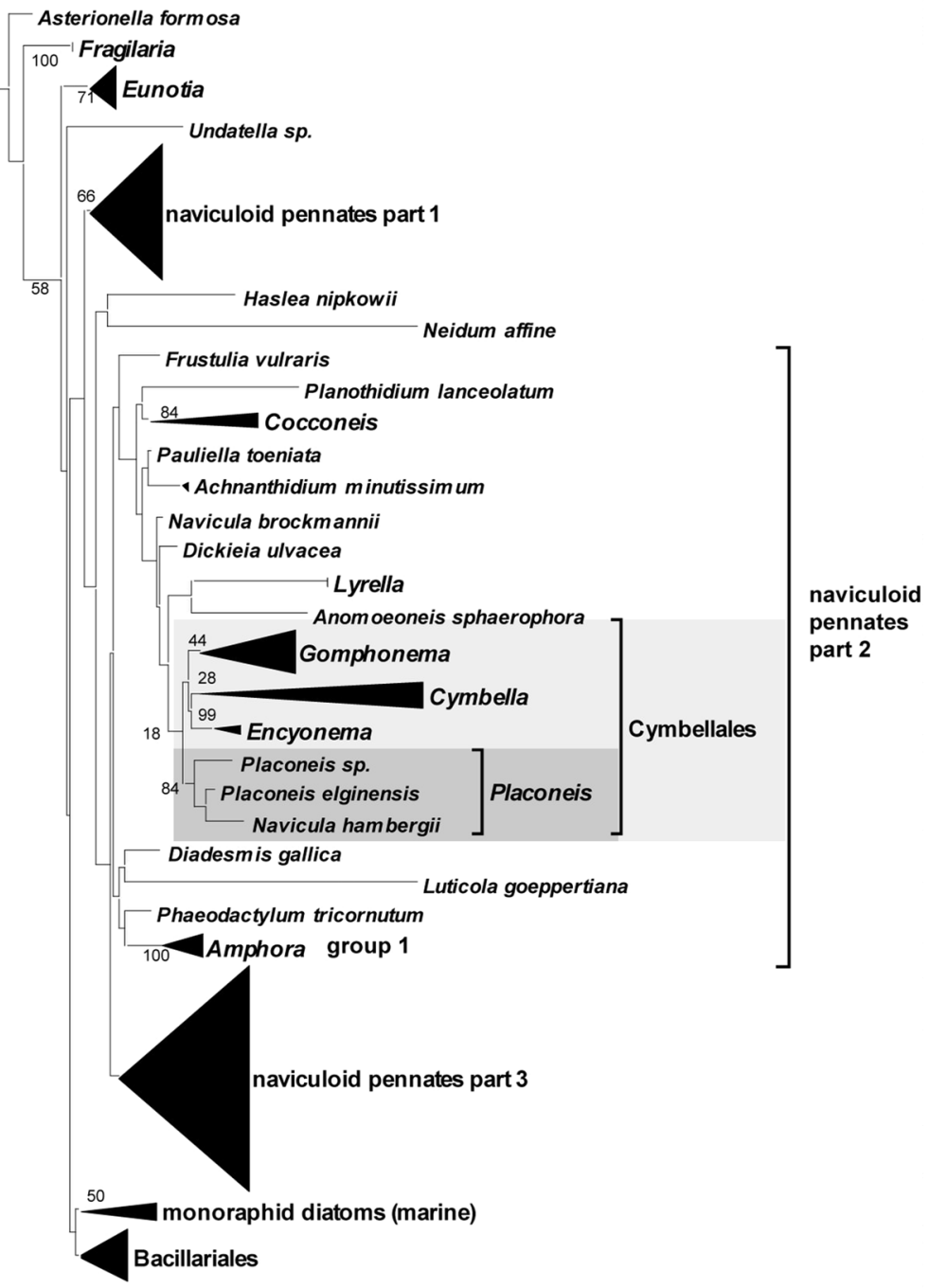

Fig. 2. Phylogeny inferred with the ML analysis using SSU rDNA sequences from GenBank and the AlgaTerra cultures. Bootstrap values obtained from 1000 replications based on NJ analyses ( GTR $+\mathrm{I}+\mathrm{G}$ model) have been plotted at the nodes. Condensed regions will be shown in detail in separate papers.

Although it was already known that $N$. hambergii did not belong to Navicula sensu stricto (e.g., Krammer and Lange-Bertalot 1986), the species had not been reassigned to another genus, although Metzeltin et al. (2004, p. 8) noted that "Navicula hambergii belongs very probably to Placoneis". All features defining 


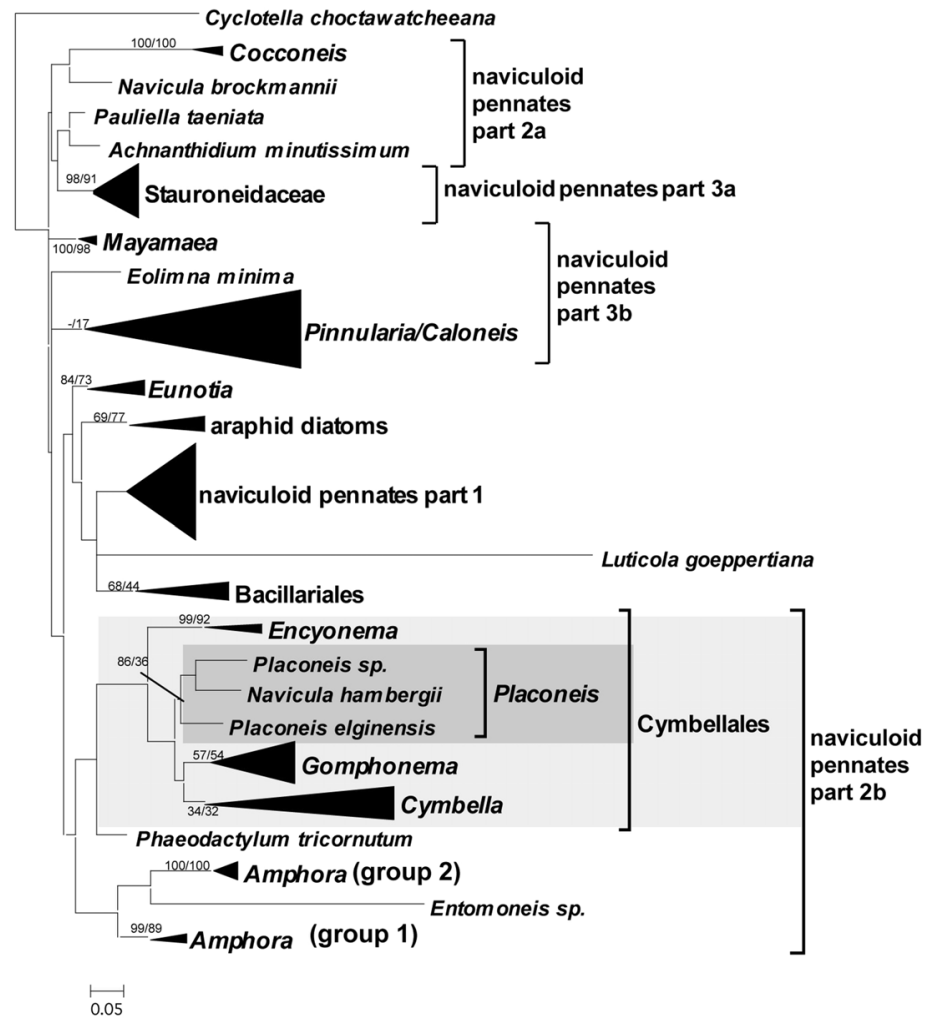

Fig. 3. Details of the ML tree analysis from LSU rDNA sequences from GenBank and AlgaTerra cultures. Bootstrap values obtained from 1000 replications based on NJ analyses using GTR $+\mathrm{I}+\mathrm{G}$ model and on parsimony analyses have been plotted at the nodes. Collapsed clades will be discussed in future papers.

Placoneis were found in N. hambergii and supported its transfer to Placoneis. Morphological investigations of Navicula hambergii and Placoneis elginensis indicated that these two species were near relatives. The single chloroplast, with a central bridge from which lobes project into the four quadrants of the cell (Figs 6, $7,13,14)$, is typical for species belonging to Placoneis. The striae are radiate (Figs 8,15 ). At the centre of the valve the striae are irregularly abbreviated (P. elginensis, Figs 8, 12) or alternately longer and shorter $(N$. hambergii, Figs 15, 19). With SEM it can be seen, that, externally, the striae consist of small round areolae (Figs 12, 19). Internally, the areolae are almost square and closed by vola-like occlusions (Figs 9, 16). Both species have a straight raphe with slightly expanded external central endings and at both poles the hook-like raphe fissures curve to the same side (Figs 8, 12,15,19). The internal central raphe endings of both species are hooked (Figs 11,18) and the internally helictoglossae at the polar raphe endings are straight and knob-like (Figs 10, 17). 


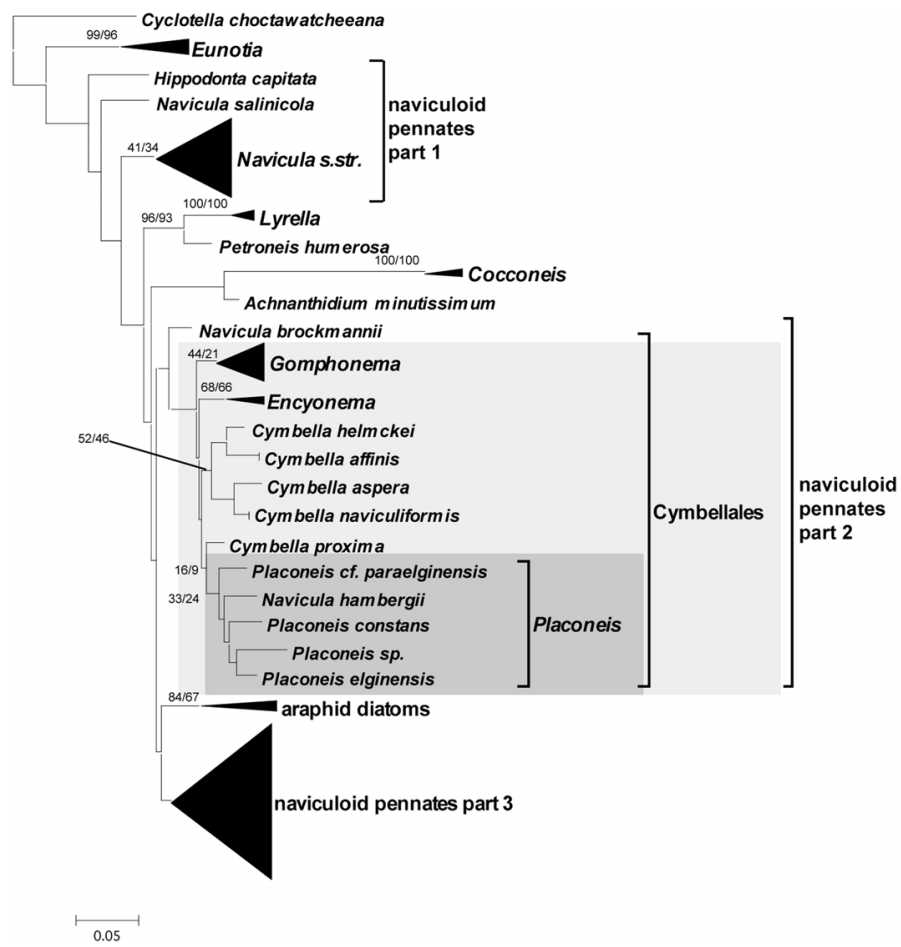

Fig. 4. Details of the ML tree analysis from $r b c \mathrm{~L}$ sequences from GenBank and the AlgaTerra cultures. Bootstrap values obtained from 1000 replications based on $\mathrm{NJ}$ analyses using GTR $+\mathrm{I}+\mathrm{G}$ model and on parsimony analyses have been plotted at the nodes. Collapsed clades will be discussed in future papers.

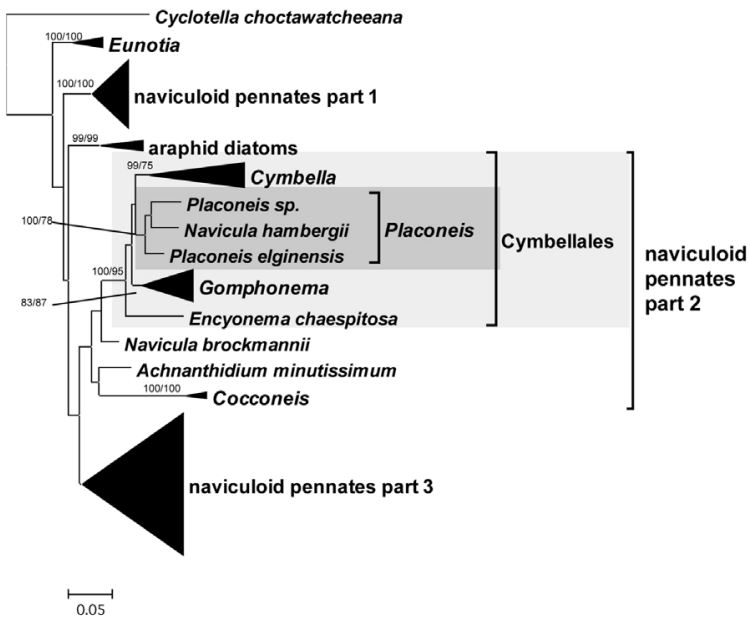

Fig. 5. Phylogeny inferred with the ML analysis using the combined dataset of SSU rDNA, LSU rDNA and $r b c \mathrm{~L}$ sequences from the AlgaTerra cultures. Bootstrap values obtained from 1000 replications based on NJ analyses using JC model and on parsimony analyses have been plotted at the nodes. Condensed clades will be shown in future papers. 


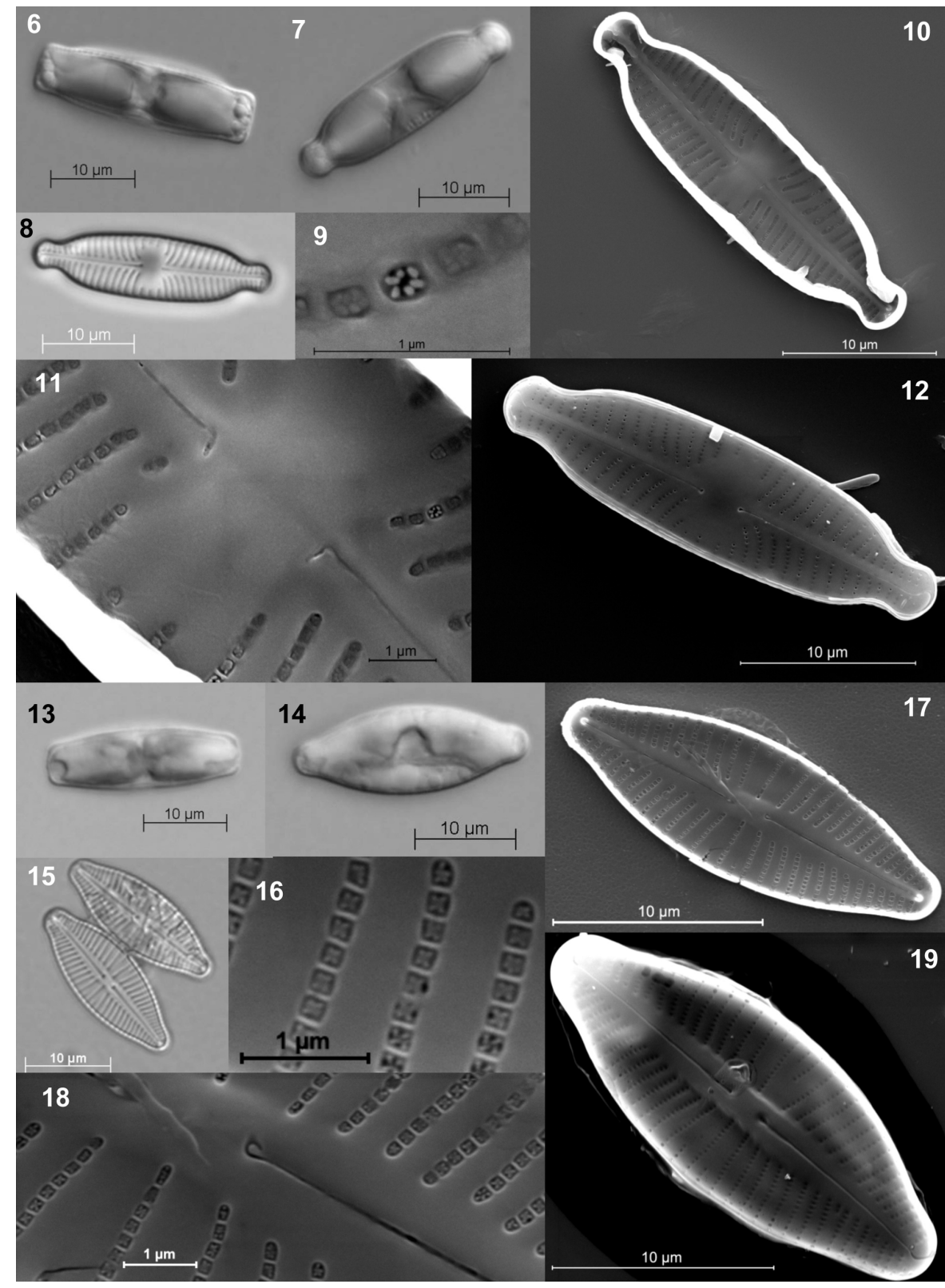

Figs 6-12. Placoneis paraelginensis. Fig. 6. Girdle view of living cell, LM. Fig. 7. Valve view of living cell, LM. Fig. 8. Cleaned valve, LM. Fig. 9. Detail areolae, SEM, showing valve interiors. Fig. 10. Internal valve view with attached girdle bands. Fig. 11. Detail of internal central raphe endings, SEM. Fig. 12 External valve view, SEM. Figs 13-19. Navicula hambergii. Fig. 13. Girdle view, LM. Fig. 14. Valve view, LM. Fig. 15. Cleaned valve. Fig. 16. Detail of areolae, SEM. Fig. 17. Internal valve view, SEM. Fig. 18. Detail of internal central raphe endings, SEM. Fig. 19. External valve view, SEM. 


\section{Discussion}

Mereschkowsky described the genus Placoneis in 1903 and used P. exigua as the type species. With this genus he separated a group of species from Navicula sensu lato, which have a single, asymmetrical chloroplast. Cox (1987) re-erected the genus and chose $P$. gastrum as the type species, because "delineation and nomenclature of $P$. exigua are confused" (Cox 1987, p. 153). In the same paper and a second investigation, (Cox 2003) she added several morphological features from SEM investigations to the description of the genus. One of the most important features of the genus Placoneis is the single chloroplast with a central bridge and lateral lobes, which lies under the valves. This is the feature that allies them most easily with the Cymbellales, a feature noted as early as 1891 by Cleve. The cells are symmetrical and parallel or elliptical sided in their central region. The striae are radiate near the centre of the valve, becoming more parallel at the apices. They are composed of small round areolae, which are internally closed by volae. The usually straight raphe slits lie in a narrow axial area. Externally, the central raphe endings are straight and slightly expanded and the polar raphe endings curve to the same side. The internal central raphe endings are usually deflected to the same side and at the internal polar end small helictoglossae are present, another feature shared with the Cymbellales. Reproductive features shared by the two genera are discussed in Mann and Stickle (1995).

These characters are distinct from Navicula sensu stricto and the separation/resurrection of Placoneis initially substantiated from morphological data is now supported from molecular data. In two of the molecular analyses, including the final combined analysis of all three genes, Placoneis was sister to Cymbella. Likewise, in the combined analysis and one other analysis, Gomphonema and Encyonema are basal to the Placoneis/Cymbella clade. Other new taxa assigned to the Cymbellales by Krammer (1982) and Krammer (1997) are not represented in this study because there were no cultures available for molecular analysis.

In a cladistic analysis of protoplast and frustular features of naviculoid diatoms, Cox and Williams (2006) obtained different phylogenetic positions for Placoneis depending on which characters were used in the analysis. Using all features, Placoneis appeared as an outgroup clade. The remaining Cymbellales are together in another more derived clade. This is because Placoneis differed very little from the features they considered as primitive in the naviculoid diatoms. Placoneis contained states other than the primitive state in nine out of the 35 characters that they coded. Of these nine characters, six of them are plastid characters and in the analysis of plastid data alone, Placoneis groups with the other Cymbellales, as it does in the nuclear molecular data, although Placoneis is not resolved as a monophyletic genus with their cladistic analysis. When the frustule data are partitioned from the other data, then Placoneis fell as a monophyletic genus as part of an unresolved polytomy of naviculoid genera. The frustular features of Placoneis that separate it primarily from the Cymbellales are the structure of the areolae coverings and the symmetry of the cell. In Placoneis, the areolae are closed by a distinct cribrum, which has been termed a rota and the cells are seldom dorsiventral (Cox \& Williams 2006). Cox (2004) reassessed the structure and terminology for pore occlusions in the raphid diatom. She gave a new name for 
the pore occlusion in Placoneis, the tectulum. This covering is placed over the internal opening to the areolae (Cox, 2004, fig. 21) and the external opening is unobstructed. In contrast, other members of the Cymbellales have the external opening of the areolae constricted or expanded in some manner from the virgae of the striae. There is no cribrum closing the internal opening of the areolae. The variety of constriction/expansions from the exernal opening of the areolae are illustrated in Cox (2004, figs 24-27). This is likely one of the features separating Placoneis from the remaining Cymbellales; from our molecular tree, it could be interpreted that the Cymbellales have lost the cribrum, which has been retained by its basal member, Placoneis. Instead the Cymbellales have modified the external opening of the areolae by extensions from the striae across the areolar opening.

Based on the results of the molecular and morphological analyses of Navicula hambergii a new combination must be made:

Placoneis hambergii (Hustedt) Bruder comb. nov. (Fig. 6).

BASIONYM: Navicula hambergii Hustedt (1924, Die Bacillariaceen-Vegetation des Sarekgebirges. In: Hamberg, A. (ed.): Naturwissenschaftliche Untersuchungen des Sarekgebirges in SchwedischLappland, Botanik 3 (6): p. 562, pl. 17: fig. 2).

\section{Acknowledgement}

We thank Sabine Strieben for technical assistance. This work was supported by the BMBF project ALGATERRA.

\section{References}

ANDERSEN, R.A., S.L. MORTON \& J.P. SEXTON (1997): CCMP - Provasoli-Guillard National Center for Culture of Marine Phytoplankton. - J. Phycol. 33 (Suppl.): 1-75.

BESZTERI, B., E. ACS, J. MAKK, G. KOVACS, K. MARIALIGETI \& K.T. KISS (2001): Phylogeny of six naviculoid diatoms based on 18 S rDNA sequences. - Int. J. Syst. Evol. Microbiol. 51: 1581-1586.

CLEVE, P.T. (1895): Synopsis of the naviculoid diatoms. Part 2. - Kongl. Svenska Vetensk. Acad. Handl. 27: 1-219.

COX, E.J. (1987): Placoneis Mereschkowsky: the re-evaluation of a diatom genus originally characterized by its chloroplast type. - Diatom Res. 2: 145-157.

COX, E.J. (1988): Taxonomic studies on the diatom genus Navicula. V. The establishment of Parlibellus gen. nov. for some members of Navicula sect. Microstigmaticae. - Diatom Res. 3: 9-38.

COX, E.J. (2003): Placoneis Mereschkowsky (Bacillariophyta) revisited: resolution of several typification and nomenclatural problems, including the generitype. - Bot. J. Linn. Soc. 141: 53-83.

COX, E.J. (2004): Pore occlusion in raphid diatoms - a reassessment of their structure and terminology, wtih particular reference to members of the Cymbellales. - Diatom 20: 33-46.

COX, E.J. \& D.M. WILLIAMS (2006): Systematics of naviculoid diatoms (Bacillariophyta): a preliminary analysis of protoplast and frustule characters for family and order level classification. - Syst. Biodivers. 4: 385-399.

DAUGBJERG, N. \& R.A. ANDERSEN (1997): A molecular phylogeny of the heterokont algae based on analyses of chloroplast-encoded rbcL sequence data. - J. Phycol. 33: 1031-1041. 
DRAISMA, S.G.A. \& W.F. PRUD'HOMME VAN REINE (electronic scource): Phylogeny of the Phaeophyceae. - http://www.nationaalherbarium.nl/taskforcemolecular/old_projects.htm

EHARA, M., Y. INAGAKI, K.I. WATANABE \& T. OHAMA (2000): Phylogenetic analysis of diatom coxI genes and implications of a fluctuating GC content on mitochondrial genetic code evolution. - Curr. Genet. 37: 29-33.

ELWOOD, H.J., G.J. OLSEN \& M.L. SOGIN (1985): The small subunit ribosomal RNA gene sequences from the hypotrichous ciliates Oxytricha nova and Stylonychia pustulata. - Molec. Biol. Evol. 2: 399-410.

EPPLEY, R.W., R.W. HOLMES \& J.D.H. STRICKLAND (1967): Sinking rates of marine phytoplankton measured with a fluorometer. - J. Exp. Mar. Biol. Ecol. 1: 191-208.

FELSENSTEIN, J. (2004): Inferring phylogenies. - Sinauer Associates, Sunderland, Massachusetts.

FILATOV, D.A. (2002): ProSeq: A software for preparation and evolutionary analysis of DNA sequence data sets. - Molec. Ecol. Notes 2: 621-624.

FOX, M.G. \& U.M. SORHANNUS (2003): RpoA: a useful gene for phylogenetic analysis in diatoms. - J. Eukar. Microbiol. 50: 471-475.

HUSTEDT, F. (1924): Die Bacillariaceen-Vegetation des Sarekgebirges. - In: HAMBERG, A. (ed.): Naturwissenschaftliche Untersuchungen des Sarekgebirges in Schwedisch-Lappland, Botanik 3 (6): 525-626. Stockholm.

HUSTEDT, F. (1930): Bacillariophyta (Diatomeae). - In: PASCHER, A. (ed.): Die SüsswasserFlora Mitteleuropas, Heft 10 (2. Aufl.): 1-466. Gustav Fischer, Jena.

KARAYEVA, N.I. (1978): A new suborder of diatoms [In Russian]. - Bot. Zhurn. (Moscow \& Leningrad) 63: 1747-1750.

KRAMMER, K. (1982): Valve morphology in the genus Cymbella C.A. Aghard. - In: HELMCKE, J.-G. \& K. KRAMMER (eds): Micromorphology of diatom valves. XI: 1-299. Cramer, Vaduz, Liechtenstein.

KRAMMER, K. (1997): Die cymbelloiden Diatomeen, eine Monographie der weltweit bekannten Taxa. Teil 2. Encyonema part., Encyonemopsis and Cymbellopsis. - Biblioth. Diatomol. 37: 1-469.

KRAMMER, K. \& H. LANGE-BERTALOT (1986): Bacillariophyceae, 1. Teil: Naviculaceae. - In: ETTL, H., J. GERLOFF, H. HEYNIG \& D. MOLLENHAUER (eds): Süsswasserflora von Mitteleuropa 2/1: 1-876. Gustav Fischer Verlag, Stuttgart.

LANGE-BERTALOT, H. (1997): Frankophila, Mayamaea und Fistulifera: drei neue Gattungen aus der Klasse Bacilariophyceae. - Arch. Protistenk. 148: 65-76.

LANGE-BERTALOT, H., D. METZELTIN \& A. WITKOWSKI (1996): Hippodonta gen. nov. - Umschreibung und Begründung einer neuen Gattung der Naviculaceae. - Iconogr. Diatomol. 4: 247-275.

LUDWIG, W. \& H.-P. KLENK (2001): Overview: A phylogenetic backbone and taxonomic framework for procaryotic systematics. - In: BOONE, D.R., R.W. CASTENHOLZ \& G.M. GARRITY (eds): Bergey's manual of systematic bacteriology (2nd ed.) 1: 49-65. Springer, New York.

MANN, D.G. (1989): The diatom genus Sellaphora: separation from Navicula. - Brit. Phycol. J. 24: 1-20.

MANN, D.G. (1994): Auxospore formation, reproductive plasticity and cell structure in Navicula ulvacea and the resurrection of the genus Dickieia (Bacillariophyta). - Eur. J. Phycol. 29: 141-157.

MANN, D.G., G.E. SIMPSON, H.J. SLUIMAN \& M. MÖLLER (2001): $R b c$ L gene tree of diatoms: a second large data-set for phylogenetic reconstruction. - Phycologia 40: 1-2. 
MANN, D.G. \& A.J. STICKLE (1985): Meiosis, nuclear cyclosis, and auxospore formation in Navicula sensu stricto (Bacillariophyta). - Brit. Phycol. J. 24: 167-181.

MEDLIN, L.K., H.J. ELWOOD, S. STICKEL \& M.L. SOGIN (1988): The characterization of enzymatically amplified eukaryotic 16S-like rRNA-coding regions. - Gene 71: 491-499.

MEDLIN, L.K., W.H.C.F. KOOISTRA, R. GERSONDE \& U. WELLBROCK (1996): Evolution of the diatoms (Bacillariophyta). II. Nuclear-encoded small-subunit rRNA sequence comparisons confirm a paraphyletic origin for the centric diatoms. - Molec. Biol. Evol. 13: 67-75.

MEDLIN, L.K. \& I. KACZMARSKA (2004): Evolution of the diatoms: V. Morphological and cytological support for the major clades and a taxonomic revision. - Phycologia 43: 245-270.

MEDLIN, L.K., W.H.C.F. KOOISTRA, R. GERSONDE \& A.M. SCHMID (2000): A review of the evolution of the diatoms - a total approach using molecules, morphology and geology. - In: WITKOWSKI, A. \& J. SIEMINSKA (eds): The origin and early evolution of diatoms: fossil, molecular and biogeographical approaches: 13-35. Polish Acad. Sciences, Krakow.

MERESCHKOWSKY, C. (1903): Über Placoneis, ein neues Diatomeen-Genus. - Beih. Bot. Centralbl. 15: 1-29.

METZELTIN, D., H. LANGE-BERTALOT \& F. GARCIA-RODRIGUEZ (2004): Diatoms of Uruguay. - Iconogr. Diatomol. 15: 1-736.

POSADA, D. \& K.A. CRANDALL (1998): Modeltest: testing the model of DNA substitution. - Bioinformatics 14: 817-818.

ROUND, F.E., R.M. CRAWFORD \& D.G. MANN (1990): The diatoms: Biology and morphology of the genera. - Cambridge University Press, Cambridge.

SAIKI, R.K., D.H. GELFAND, S. STOFFEL, S.J. SCHARF, R. HIGUCHI, G.T. HORN, K.B. MULLIS \& H.A. ERLICH (1988): Primer-directed enzymatic amplification of DNA with a thermostable DNA polymerase. - Science 239: 487-491.

SARNO, D., W.H.C.F. KOOISTRA, L. MEDLIN, I. PERCOPO \& A. ZINGONE (2005): Diversity in the genus Skeletonema (Bacillariophyceae). II. An assessment of the taxonomy of S. costatum-like species with the description of four new species. - J. Phycol. 41: 151-176.

SCHILLER, W. \& H. LANGE-BERTALOT (1997): Eolimna martinii n. gen., n. sp. (Bacillariophyceae) aus dem Unter-Oligozän von Sieblos/Rhön im Vergleich mit ähnlichen rezenten Taxa. - Paläontol. Z. 71: 163-172.

SIMONSEN, R. (1974): The diatom plankton of the Indian Oceaan Expedition of R/V Meteor 1964-5. - Meteor Forschungsergebn., D 19: 1-107.

SOLTIS, D.E. \& P.S. SOLTIS (1998): Choosing an approach and an appropriate gene for phylogenetic analysis. - In: SOLTIS, D.E., P.S. SOLTIS \& J.J. DOYLE (eds): Molecular systematics of plants. II: 1-42. Kluwer Academic Publishers, Boston.

SWOFFORD, D.L. (1998): PAUP*. Phylogenetic analysis using parsimony (* and other methods). Version 4.0b10. - Sinauer Associates, Sunderland, Massachusetts.

SWOFFORD, D.L., G.J. OLSEN, P.J. WADDELL \& D.M. HILLIS (1996): Phylogenetic inference. - In: HILLIS, D.M., C. MORITZ \& B.K. MABLE (eds): Molecular systematics: 407-514. Sinauer Associates, Sunderland, Massachusetts.

THOMPSON, J.D., T.J. GIBSON, F. PLEWNIAK, F. JEANMOUGIN \& D.G. HIGGINS (1997): The CLUSTAL_X windows interface: flexible strategies for multiple sequence alignment aided by quality analysis tools. - Nucl. Acids Res. 25 (24): 4876-4882.

VAN DER AUWERA, G. \& R. DE WACHTER (1998): Structure of the large subunit rDNA from a diatom, and comparison between small and large subunit ribosomal RNA for studying stramenopile evolution. - J. Eukar. Microbiol. 45: 521-527. 
WITKOWSKI, A., H. LANGE-BERTALOT \& K. STACHURA (1998): New and confused species in the genus Navicula (Bacillariophyceae) and the consequences of the restricrive generic circumscription. - Cryptog. Algol. 19: 83-108.

Received 4 February 2007, accepted in revised form 30 May 2007. 